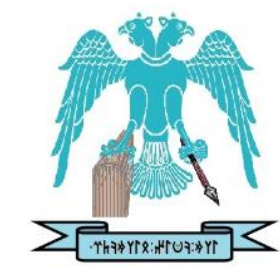

JOURNAL OF ENERGY SYSTEMS

$2021,5(1)$

\title{
Dynamic analysis of a tri-floater with vertical axis wind turbine supported at its centroid
}

\author{
Asadulla Thoppil \\ MES College of Architecture, Kozhikode, Kerala, India, t.asadulla@gmail.com
}

M. Abdul Akbar (D)

Department of Civil Engineering, Dr B R Ambedkar National Institute of Technology, Jalandhar (Punjab), India, maakbar83@yahoo.co.in

Dadi Rambabu (D)

Department of Civil Engineering, Dr B R Ambedkar National Institute of Technology, Jalandhar (Punjab), India, dadir.ce.19@nitj.ac.in

\begin{abstract}
The paper deals with the dynamic analysis of a tri-floater with a $1 \mathrm{MW}$ offshore Vertical Axis Wind Turbine (VAWT) placed at its centroid. Six line catenary mooring system was used for controlling the horizontal movement of the floater. The floater was modeled as a rigid body with six degrees of freedom. Mass, damping and hydrostatic stiffness were calculated by using hydrostatic stability condition. The aerodynamic load on Vertical Axis Wind Turbine was calculated via the stream tube theory. Wave profile was calculated using Airy's wave theory followed by the use of Morison's equation to determine the inertial and drag forces on the floater. A computer program was developed by using the MatLab package for force calculation including wind and wave excitations as a dynamic analysis. The Newmark - beta method was performed for these analyses. The equation of motion for the floater was solved in time domain. Restoring force by mooring lines at each instant of time was calculated based on the cable profile. Responses of the tri-floater with VAWT in different sea conditions were analyzed. It was proven that surge, heave and pitch are the predominant motions for a straight $(00)$ wave. These motions were also analyzed for the waves with different inclinations and their responses were also considered and compared.
\end{abstract}

Keywords: Dynamic analysis, Offshore wind turbine, Tri-floater, Wind energy, Vertical axis wind turbine

Cite this paper as:

Thoppil, A., Akbar, A.A., \& Rambabu, D Dynamic analysis of a tri-floater with vertical axis wind turbine supported at its centroid. Journal of Energy Systems 2021, 5(1), 10-19, DOI: $10.30521 /$ jes. 811097

(C) 2021 Published by peer-reviewed open access scientific journal, JES at DergiPark (https://dergipark.org.tr/en/pub/jes) 


\section{INTRODUCTION}

Offshore wind energy has a promising future for the ample wind resources and the steadily evolving wind turbine technology. Compared to the land-based wind energy plants, the concept of offshore wind energy is more attractive in many aspects, including more consistent and stronger winds, less noise and pollution concerns, etc. Wind turbines are mainly classified as Horizontal Axis Wind Turbines (HAWT) and Vertical Axis Wind Turbines (VAWT). VAWTs have many well-known advantages over HAWTs, which could be potentially magnified in offshore applications [1]. For example, VAWTs have lower centers of gravity, much less sensitivity to extreme wind conditions, and superior up-scaling potentials than their HAWT counter parts. Here, responses of the tri-floater with VAWT in different sea conditions were analyzed and it was found that surge, heave and pitch are the predominant motions for a straight $\left(0^{0}\right)$ wave. These motions can be analyzed for the waves with different inclinations and the responses are studied and compared as well.

Hooft [2] studied the hydrodynamic aspects of semi-submersible platforms, by subdividing the structure into slender and simpler elements. The forces on each member were calculated by using Morison's approach and the forces were summed up assuming that the hydrodynamic properties of each element of the submerged construction were not influenced by the neighboring elements. Tong [3] explored the conceptual design of a float consisting of a steel tripod space frame with the wind turbine mounted on it. The tower was bolted onto the deck of a concrete cylindrical buoy hull with a wide bottom disk consisting of 8 line catenary mooring system to control the motion. A 1.4 MW offshore wind turbine was provided for locations, where the water depth varied between $100 \mathrm{~m}$ to $300 \mathrm{~m}$. In other study, Bulder and co-workers [4] presented the technical and economic feasibility of floating wind energy systems for water depths greater than $50 \mathrm{~m}$. In their work, a cost analysis was carried out on different floating platforms and it was concluded that Tri-floater was the best option. Ruoyu and co-workers [5] studied the dynamic behavior of a semi-submersible floating foundation of a $600 \mathrm{~kW}$ capacity wind turbine in $60 \mathrm{~m}$ deep water by considering the coupled load effects of wind turbine-tower-floating foundation, mooring lines and the ocean environment. Borg and co-workers [6] presented different models of VAWTs with suitable floating platforms and studied different approaches to model the mooing systems by focusing on the behavior of the structure at the preliminary stages of design, adequately. Owen and Griffithy [7] studied the vibration and kinetic stability of large-scale floating VAWTs considering rigidflexible couplings, and developed a software package. Rajeswari and Nallayarasu [8] conducted experimental and CFD studies on the hydrodynamic responses of a scaled VAWT with three column semi-submersible floater. In a different study, Ramtin and co-workers [9] analyzed the fatigue life sensitivity of monopole - supported offshore wind turbines under operational and non-operational conditions using time domain finite element simulations. They asserted that the fatigue life increased significantly due to the reductions in the bending stress caused by the increased damping. Islam and coworkers [10] presented a thorough review on the aerodynamic models of the straight-bladed VAWTs. Blonk [11] conducted research on the technical and economic feasibility of two floating VAWT concepts by using simplified BEM and hydrostatic models. Similar fully-coupled numerical models have also been used to test different floating VAWT model concepts [12,13,14,15,16,17,18,19].

\section{MODEL DESCRIPTION AND METHODOLOGY}

\subsection{Methodology}

To predict the response of a floating wind turbine system in wind and wave environment, a computational model for dynamic analysis is proposed to be developed which considers both wave loading on the submerged floater and the aerodynamic loading on VAWT. Forces and moments due to 
gravity, wind and waves are exerted on both the wind turbine assembly and floater. Wind forces and moments are primarily exerted on the rotor of the wind turbine and supporting tower, while wave forces act only on the floater. The forces and moments are produced on the wind turbine blades and supporting tower are transferred to the floater. Those resulting oscillatory forces and moments cause some dynamic displacements on the floating wind turbine system. The floating wind turbine system needs to be designed so that it should withstand the most severe sea state expected to be encountered during its lifetime. The floating structure must support its own weight and that of the wind turbine. A tri-floater semi-submersible has three columns connected by pontoons. As the column and pontoon diameters are small, Morison's formulation is performed for the wave force calculation. Mooring system response is assumed to be quasi-static. Dynamics of mooring lines is not considered as it will not have much impact on the results as the turbine is installed in shallow water. The analysis is performed in the time domain and the equilibrium equation is solved by using Newmark-beta method.

The different parameters of the tri-floater are given in Table 1 and the plan view of the tri-floater as it supports the Vertical Axis Wind Turbine is shown in Fig. 1.

Table 1. Basic floater dimensions.

\begin{tabular}{ll}
\hline Item description & Dimension \\
\hline Column diameter & $7.7 \mathrm{~m}$ \\
Column height & $24 \mathrm{~m}$ \\
Column draft & $12 \mathrm{~m}$ \\
Distance between column centers & $68 \mathrm{~m}$ \\
Pontoon diameter & $3.3 \mathrm{~m}$ \\
Heave plate diameter & $15.4 \mathrm{~m}$ \\
Total volume displacement & $3078 \mathrm{~m}^{3}$ \\
\hline
\end{tabular}

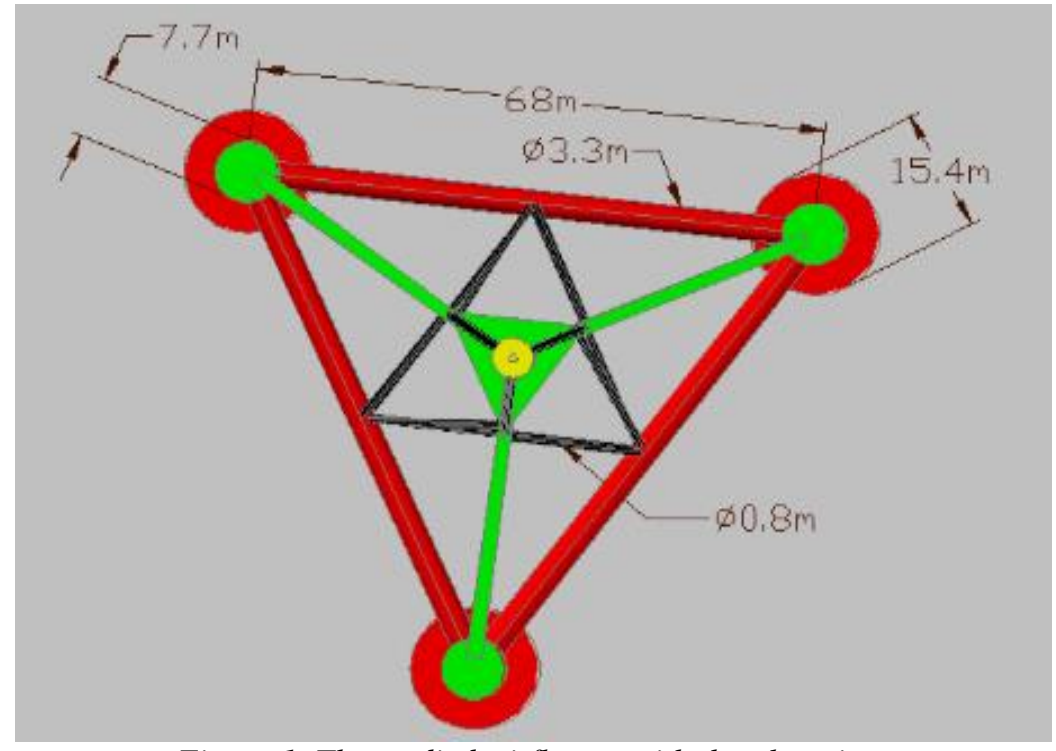

Figure 1. The studied tri-floater with the plan view.

The VAWT is placed symmetrically on the centroid of the triangle formed by the tri-floater. The distance between the centers of the columns is $68 \mathrm{~m}$. The properties of the VAWT are given in Table 2 and 3D view is shown in Fig. 2. The proportioning of the VAWT (radius, height, etc.) ensures a rated power scale $P=1 \mathrm{MW}$. A 3-bladed VAWT is also considered with its simplest NACA0012 shape with the corresponding aerofoil. 
Table 2. Turbine and tower dimensions.

\begin{tabular}{ll}
\hline Item description & Specification \\
\hline Machine rated power & $1 \mathrm{MW}$ \\
Rotor diameter & $38 \mathrm{~m}$ \\
Blade cross section & NACA0012 \\
Blade chord & $0.5334 \mathrm{~m}$ \\
Length of blade & $17.01 \mathrm{~m}$ \\
Height of hub & $83 \mathrm{~m}$ above sea water level \\
Rated rotor speed & 27 rotations per minute \\
Tower base diameter & $7.5 \mathrm{~m}$ (hollow) \\
Tower top diameter & $4.5 \mathrm{~m}$ \\
Length of tower & $70 \mathrm{~m}$ \\
Centre of gravity of tower & $31.8 \mathrm{~m}$ above tower base \\
Tower weight & $3528 \mathrm{kN}$ \\
Total machine weight & $3352 \mathrm{kN}$ \\
\hline
\end{tabular}

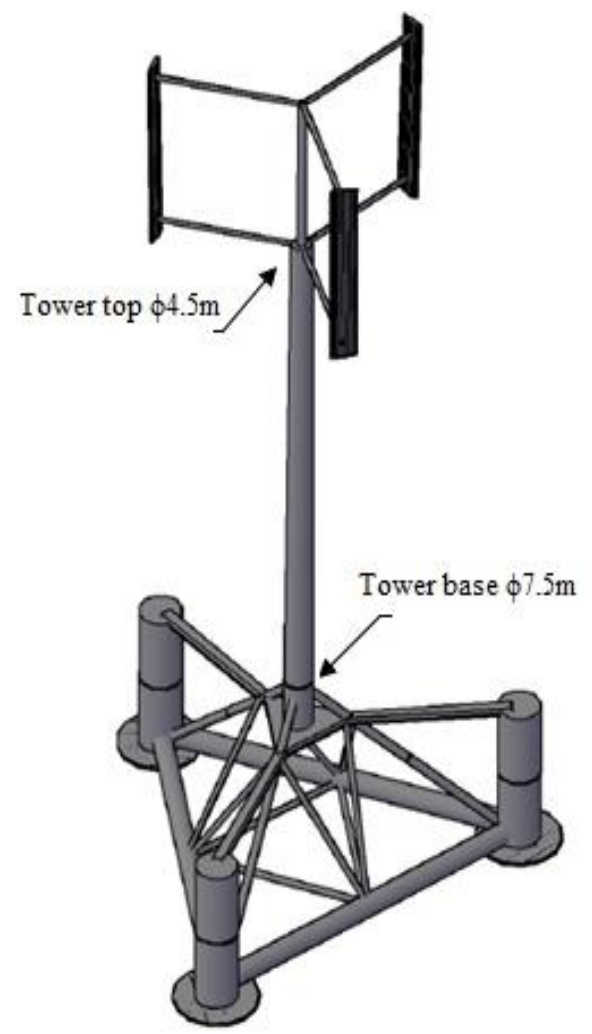

Figure 2. Tri-floater with VAWT

\section{AERODYNAMIC ANALYSIS}

\subsection{Wind Speed}

External wind conditions in the offshore regime is defined in guidelines by Det Norske Veritas (DNV), International Electro technical Commission (IEC) and Germanischer Lloyd (GL). The wind speed at 10 $\mathrm{m}$ is often used as the reference height in all the standards. The wind profile, $V(z)$ denotes the average 
wind speed as a function of height $z$ above the ground. According to the GL standards, the normal wind speed profile is given by the power law. The wind velocity at hub height is determined by Eq. 1 .

$$
V(z)=V\left(z_{r}\right)\left(\frac{z}{z_{r}}\right)^{\alpha} \text { for } t>T
$$

Here, $z_{r}$ and $\alpha$ are the power law exponent, which takes a value of 0.11 for all wind speeds in offshore conditions (as per GL standards). Wind velocity at the hub height varies by time. Design wind velocity is calculated from gust velocity as follows:

$$
V(z, t)=V(z)-0.37 V_{\text {gust }} \operatorname{Sin}\left(\frac{3 \pi t}{T}\right)\left(1-\cos \left(\frac{2 \pi t}{T}\right) \text { for } 0<t<T\right.
$$

where, $T$ and $V_{\text {gust }}$ are the gust characteristic time period and the largest extreme gust magnitude, respectively. Strictly, it is defined as,

$$
V_{\text {gust }}=1.53\left(V_{e 1}-V_{h u b}\right)
$$

where, $V_{e l}$ is the one-year extreme wind speed calculated from height above GL (Eq. 4) and $V_{h u b}$ is the wind speed at the hub height.

$$
V_{e 1}=1.12 V\left(z_{r}\right)\left(\frac{z}{z_{r}}\right)^{\alpha}
$$

\subsection{Wind Force on Tower}

Wind force acting on the tower produces considerable effect on the floater motion. Wind velocity increases with height, whereas the tower projected area decreases with height. The tower is divided into a number of sections and force acting on each section is determined and added to calculate the total force on the structure. To calculate the projected area of any section, the diameter of tower at any height $z$ is required and is determined by Eq. 5 .

$$
D_{z}=D_{b}\left(1-\frac{z}{H}\right)+D_{t}\left(\frac{z}{H}\right)
$$

where, $D_{z}$ is the diameter at any height $z$ from the tower base, $D_{b}$ is the tower base diameter, $D_{t}$ is tower top diameter and $H$ is the height of the tower. From the design wind velocity $(V)$, the static wind force $\left(F_{w}\right)$ acting perpendicular to an exposed area $(A)$ can be obtained from Eq. 6.

$$
F_{w}=\frac{1}{2} \rho_{a} V^{2} C_{s}
$$

where, $\rho_{a}$ is the density of air, $C_{s}$ is the shape coefficient $\left(C_{s}=0.5\right.$ for cylindrical sections). Based on these values and the dimensions given in Table 2, total force acting on the tower is calculated as 24.795 $\mathrm{kN}$.

\subsection{Loading on Wind Turbine}

Power generated by wind turbine depends on the interaction between the rotor blades and the wind. The analysis of force on the turbine is carried out by assuming a control volume, where the boundaries are the surface and two cross sections of the stream tube. The analysis is based on linear momentum theory. From the conservation of linear momentum for a 1D incompressible time-invariant flow, the thrust $(T)$ is equal and opposite to the change in momentum of air stream [20]. Here, $T$ should not be confused with period mentioned in the previous subsection. The thrust can be stated as, 


$$
T=\frac{1}{2} \rho_{a} V_{1}^{2} A(4 a(1-a))
$$

where, $A$ is the projected area of turbine blade and $a$ is the axial induction factor. Axial induction factor is given by,

$$
a=\frac{V_{1}-V_{2}}{V_{1}}
$$

where, $V_{l}$ and $V_{2}$ are the velocities of the fluid before entering the stream tube and before passing through actuator disk respectively. The thrust force on the wind turbine is characterized by a non-dimensional thrust coefficient as in,

$$
C_{t}=\frac{T}{\frac{1}{2} \rho_{a} A V^{2}}
$$

Straight bladed Darrieus type VAWT is among the simple wind turbines. However, its aerodynamic analysis is quite complex. Flow velocities in the up-stream and downstream sides of the Darrieus type VAWTs are not constant. The general mathematical expression for the geometric parameters of a VAWT for a specific location of the blade is described in Eqs. 10,11 and 12. The aerofoil shape has inherent lift and drag characteristics varying with an attack angle $(\delta)$ of the wind.

$$
\begin{gathered}
\tan \delta=\frac{V_{a} \sin \theta}{V_{a} \cos \theta+\Omega R} \\
C_{N}=C_{L} \cos \delta+C_{D} \sin \delta \\
C_{T}=C_{L} \sin \delta-C_{D} \cos \delta
\end{gathered}
$$

where, $V_{a}$ is incident wind velocity on the rotor acting as an actuator disc, $\theta$ is the momentary angular location of the aerofoil from the centre of rotor, $\Omega$ is the angular velocity of the VAWT, $R$ is the radius of the rotor, $C_{L}$ is the lift coefficient and $C_{D}$ is the drag coefficient. The instantaneous thrust force $\left(T_{i}\right)$ on a single aerofoil is given by Habtamu and co-workers [20] in Eq. 13.

$$
T_{i}=\frac{1}{2} \rho_{a} V_{R}^{2}(h c)\left(C_{T} \cos \theta-C_{N} \operatorname{Sin} \theta\right)
$$

where, $h$ is the blade height, $V_{R}$ is the relative velocity and $c$ is the chord length of blade. The aerodynamic efficiency of a wind turbine is indicated by the power coefficient $\left(C_{p}\right)$ given by Eq. 14 .

$$
C_{P}=\frac{P_{\max }}{\frac{1}{2} \rho_{a} A V^{2}}
$$

where, $P_{\max }$ is the maximum rated power of the wind turbine. The shape of aerofoil blade chosen for analysis is NACA0012. For low values of angle of incidence, the aerofoil has a high lift to drag ratio. Axial induction factor $(a)$ for the calculation of thrust force and power produced by wind turbine is determined by an iterative procedure programmed using MatLab. 


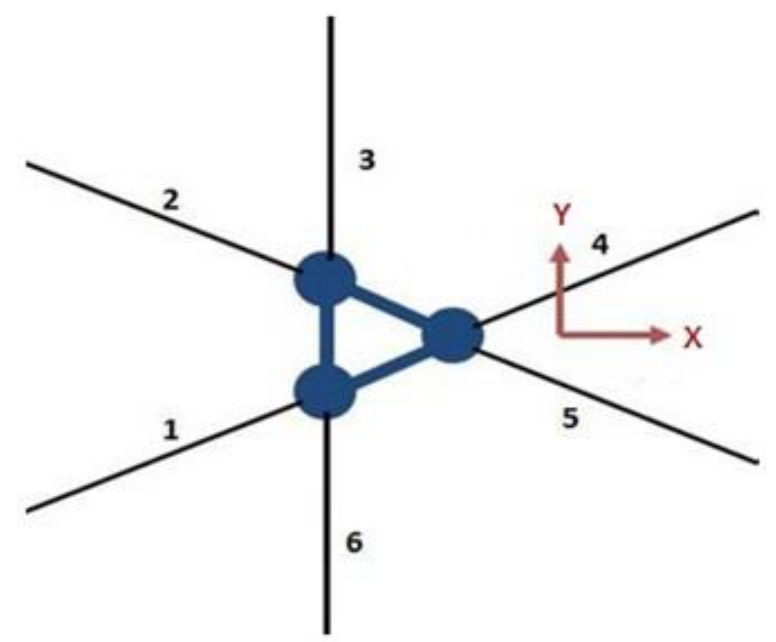

Figure 3. Mooring line configuration for the floater.

For the tri-floater, catenary mooring system is provided with 6 mooring lines. There will be 2 mooring lines connected to each leg of the floater separated by $60^{\circ}$ each as shown in Fig. 3. Studless chain of 15 $\mathrm{cm}$ diameter is used as the mooring lines.

\section{DYNAMIC ANALYSIS OF FLOATER}

Dynamic analysis of the semi-submersible floater suppording the wind turbine involves the formulation of equation of motion for the analysis of floater behavior. The forces and moments due to wind loading on the turbine blades and tower are transferred to the floater.

\subsection{Hydrodynamic Loading}

In the present study, the wave description is assumed to be regular. This simplification is based on certain arguments. Irregular wave description is used for the fatigue analysis, where the lifetime load is required. The calculations were performed for operational sea and rough sea conditions. The wind velocity, wave height and time period for operational and rough sea conditions are shown in Table 3 .

Table 3. Sea states used for analysis

\begin{tabular}{lccc}
\hline & Wind velocity $(\mathrm{m} / \mathrm{s})$ & Wave height $(\mathrm{m})$ & Time period $(\mathrm{s})$ \\
\hline Sea state 1 (operational) & 12.2 & 4.2 & 9.2 \\
Sea state 2 (rough) & 21.1 & 8.78 & 11 \\
\hline
\end{tabular}

\section{RESULTS AND DISCUSSIONS}

\subsection{General}

The system is modeled as a rigid body with six degrees of freedom. For the mathematical model developed, the hydrostatic stability check gives a feasible result. All the forces were transferred to the centre of gravity of the system as forces and moments. Input parameters used for validation are: Column diameter of $10.7 \mathrm{~m}$, pontoon diameter of $1.8 \mathrm{~m}$, pontoon length of $51.2 \mathrm{~m}$, heave plate diameter of 23.7 $\mathrm{m}$, column draft of $22.9 \mathrm{~m}$, wave height of $13.5 \mathrm{~m}$, time period of $17 \mathrm{~s}$, mass of floater of $69629 \mathrm{kN}$, mass of turbine and tower of $8369 \mathrm{kN}$ and tether diameter of $0.15 \mathrm{~m}$. 


\subsection{Validation}

To validate the computer program developed, experimental study on similar platform conducted by Dominique and co-workers [21] is also compared with our findings. Inputs to the program include the floater dimensions, wave parameters, wind thrust force and statics of tether lines.

Table 4. Comparison of results.

\begin{tabular}{clccc}
\hline \multirow{2}{*}{ Degree of freedom } & Max & Min & $\begin{array}{c}\text { Root-mean-square values } \\
\text { (RMS) }\end{array}$ \\
\hline \multirow{3}{*}{ Surge (m) } & Present work (Analytical) & 13.32 & -6.95 & 3.40 \\
& As per Dominique R et al. [21] (Experimental study) & 13.26 & -6.75 & 3.21 \\
& $\%$ Difference & 0.45 & 2.96 & 5.91 \\
& Present work (Analytical) & 4.52 & -5.89 & 1.95 \\
Heave (m) & As per Dominique R et al. [21] (Experimental study) & 4.86 & -5.84 & 1.99 \\
& \% Difference & 6.99 & 0.85 & 2.01 \\
& Present work (Analytical) & 5.07 & -3.19 & 1.36 \\
Pitch (degrees) & As per Dominique R et al. [21] (Experimental study) & 4.87 & -3.87 & 1.27 \\
& \% Difference & 4.10 & 17.57 & 7.08 \\
\hline
\end{tabular}

From Table 4, the analytical and experimental results are found to be matching closely as the percentage deviation of maximum, minimum and root-mean-square (RMS) values of surge, heave and pitch motions are less. Hence, it can be concluded that the developed MatLab program is suitable for finding the responses of the floater. It is also clear that the surge motion will be more for unidirectional regular wave acting in the surge direction of the platform coordinate system and the structure will remain in transition state for a time period much larger than that for heave and pitch motions. The amplitudes of heave and pitch responses will move to a steady state at almost the same time and the difference between the maximum amplitude of transition state and the amplitude of steady state for surge motion will be large.

Table 5. Responses for operational and rough sea conditions.

\begin{tabular}{|c|c|c|c|c|c|c|c|c|}
\hline \multirow[b]{2}{*}{$\begin{array}{l}\text { Degree of } \\
\text { freedom }\end{array}$} & \multicolumn{4}{|c|}{ Operational sea } & \multicolumn{4}{|c|}{ Rough sea } \\
\hline & Max & Min & RMS (transient+ steady) & $\begin{array}{l}\text { RMS (steady } \\
\text { state) }\end{array}$ & $\operatorname{Max}$ & Min & $\begin{array}{l}\text { RMS (transient+ } \\
\text { steady) }\end{array}$ & $\begin{array}{l}\text { RMS (steady } \\
\text { state) }\end{array}$ \\
\hline Surge (m) & 1.1739 & -0.8571 & 0.2688 & 0.1964 & 5.3509 & 5.6929 & 1.3146 & 0.915 \\
\hline Heave (m) & 0.6391 & -0.808 & 0.2353 & 0.2268 & 3.2543 & -3.847 & 1.2604 & 1.2243 \\
\hline Pitch (degrees & 0.2967 & -0.0157 & 0.1613 & 0.1611 & 1.0436 & 0.4777 & 0.3216 & 0.3070 \\
\hline
\end{tabular}

Dynamic analysis is performed separately for both operational and rough sea conditions. Only the responses in surge, heave and pitch directions are predominant and responses in other directions are negligible. Table 5 gives the maximum, minimum and root-mean-square (RMS) values of surge, heave and pitch motions of floater for operational sea conditions and rough sea conditions. Due to large wave force acting on the structure in rough sea conditions, the floater responses in surge, heave and pitch have larger variation to that in operational sea conditions. For rough sea conditions, the maximum response values of surge, pitch and heave are increased by $356 \%, 409 \%$ and $252 \%$, respectively when compared with operational sea conditions. The maximum of heave response in rough sea is only $3.2543 \mathrm{~m}$ indicating that sufficient free board would be available. For both sea conditions, surge response is less on comparison with the overall dimensions of the tri-floater indicating its high stability.

\subsection{Response for Various Inclinations of Wave}

Surge, heave and pitch responses of tri-floater are computed for $0^{\circ}, 30^{\circ}, 45^{\circ}$ and $60^{\circ}$ inclinations of the wave with $x$-axis (as shown in Fig. 3) in operational sea condition (Table 6). 
Table 6. Maximum response values for $0^{\circ}, 30^{\circ}, 45^{\circ}$ and $60^{\circ}$ inclinations of wave.

\begin{tabular}{ccccc}
\hline Degree of freedom & $0^{\circ}$ wave & $30^{\circ}$ wave & $45^{\circ}$ wave & $60^{\circ}$ wave \\
\hline Surge $(\mathrm{m})$ & 1.1739 & 1.0008 & 0.8343 & 0.6199 \\
Heave $(\mathrm{m})$ & 0.6391 & 0.6327 & 0.5765 & 0.4842 \\
Pitch (degrees) & 0.2967 & 0.2663 & 0.2383 & 0.2030 \\
\hline
\end{tabular}

From Table 6, it is clear that surge, heave and pitch degrees of freedom have maximum response values for $0^{0}$ inclination of wave. The values are found to be reducing as the inclination of wave varies from $0^{0}$ to $60^{\circ}$. The percentage reduction of maximum response value of surge from $0^{\circ}$ to $60^{\circ}$ is high. A decrease of $15 \%$ is found in the maximum response value of surge as the inclination of wave in operational sea conditions changes from $0^{\circ}$ to $30^{\circ}$. Between $0^{\circ}$ and $45^{\circ}$, the maximum response decreases by $29 \%$ and between $0^{\circ}$ and $60^{\circ}$, it yields to $47 \%$. The percentage reduction of maximum response values of heave is less compared to that of surge as the inclination of wave changes from $0^{0}$ to $60^{\circ}$. Between $0^{0}$ and $30^{\circ}$, a decrease of $1 \%$ is observed which decreases up-to $24 \%$ for values between $0^{\circ}$ and $60^{\circ}$. Hence, the percentage reduction of maximum response values for surge is twice as that for heave between $0^{0}$ and $60^{0}$ inclinations of wave. Pitch response also shows considerable percentage reduction in maximum response values for a change of wave inclination from $0^{0}$ to $60^{\circ}$. For pitch response, the percentage reduction of maximum response value lies between the variations observed for heave and surge.

\section{CONCLUSION}

The behavior of a tri-floater supporting a vertical axis wind turbine at its centroid for different wave conditions are studied. The height of the wave in rough sea condition is found to be more than two times as compared to operational sea condition. This is the reason for large wave forces acting on tri-floater in rough sea condition. It is determined that the effect of wave is more significant compared to wind in the platform heave motion of the tri-floater. In normal operational and rough sea condition, maximum pitch is less than $2^{0}$, which proves that the efficiency of turbines is not affected. The maximum of heave response in rough sea is only $3.2543 \mathrm{~m}$, so sufficient free board would be available. For both sea conditions, the surge response is also less when compared to the overall dimensions of the tri-floater. For rough sea conditions, the pitch response attains a maximum value of $1.04^{0}$, which is less than the limiting value of $10^{\circ}$, ensuring turbine efficiency even under extreme conditions. With a change of sea condition from operational to rough, the maximum responses of surge, heave and pitch increase by $356 \%, 409 \%$ and $252 \%$ respectively. For the tri-floater, the maximum responses of surge, heave and pitch decrease as the inclination of wave changes from $0^{\circ}$ to $60^{\circ}$. The percentage reductions of maximum responses are more for the surge and less for the heave. The percentage reductions of maximum responses for the surge is two times as that for the heave between $0^{\circ}$ and $60^{\circ}$ inclinations of wave.

\section{Acknowledgment}

The authors acknowledge the computational resources provided by National Institute of Technology Calicut for the conduct of this work.

\section{REFERENCES}

[1] Sutherland, HJ, Berg, DE, Ashwill, TD. A Retrospective of VAWT Technology 2012.

[2] Hooft JP. Hydrodynamic Aspects of Semisubmersible Platform. PhD, Delft University of Technology, Delft, Nederland, 1972.

[3] Tong KC. Technical and Economic Aspects of a Floating Offshore Wind Farm. Journal of Wind Engineering and Industrial Aerodynamics 1998; I: 399-410. 
[4] Bulder BH, Henderson A, Huijsmans, Peeringa JM. Floating offshore wind turbines for Shallow waters. In: International Conference on Ocean Offshore and Arctic Engineering; 23-28 June 2002.

[5] Ruoyu, Z, Yougang, T, Jun, H, Shengfu, R, Chaohe, C. Dynamic Response in Frequency and Time Domains of a Floating Foundation for Offshore Wind Turbines. Ocean Engineering 2013; 1: 115-123, DOI: 10.1016/j.oceaneng.2012.12.015.

[6] Borg, M, Maurizio, C, Andrew, S. Offshore Floating Vertical Axis Wind Turbines, Dynamics Modelling State of the Art Part I: Aerodynamics. Renewable and Sustainable Energy Reviews 2014; 1: 1-12, DOI: 10.1016/j.rser.2014.07.096i.

[7] Owens B, Griffithy D. Modal dynamics and stability of large multi-megawatt deepwater offshore vertical-axis wind turbines: Initial support structure and rotor design impact studies. In: 32nd ASME Wind Energy Symposium Maryland, 2014; 1-21.

[8] Rajeswari K, Nallayarasu S. Hydrodynamic response of three-column semi-submersible floater supporting vertical axis wind turbine. In: ASME 2017 36th International Conference on Ocean, Offshore and Arctic Engineering. American Society of Mechanical Engineers 2017; V010T09A084-V010T09A084.

[9] Ramtin, R, Paul, F, Philippe, D. Fatigue life sensitivity of monopile-supported offshore wind turbines to damping. Renewable Energy, 2018; 1: 450-459.

[10] Islam, M, Ting, DS-K, Fartaj, A. Aerodynamic models for Darrieus-type straight-bladed vertical axis wind turbines. Renewable Sustainable Energy Rev. 2008, 12,; 1087-1109.

[11] Blonk, D.L. Conceptual Design and Evaluation of Economic Feasibility of Floating Vertical Axis Wind Turbines, 2010; 1-157.

[12] Wang K, Moan T, Hansen MOL. A method for modeling of floating vertical axis wind turbine. In: ASME 2013 32nd International Conference on Ocean, Offshore and Arctic Engineering. American Society of Mechanical Engineers, 2013; V008T09A016-V008T09A016.

[13] Collu M, Borg M, Shires A, Brennan FP. FloVAWT: progress on the development of a coupled model of dynamics for floating offshore vertical axis wind turbines. In: ASME 2013 32nd International Conference on Ocean, Offshore and Arctic Engineering. American Society of Mechanical Engineers, 2013; V008T09A045V008T09A045.

[14] Borg M, Collu M. A comparison on the dynamics of a floating vertical axis wind turbine on three different floating support structures. Energy Procedia 53 (C), 2014a; I: 268-279.

[15] Borg, M, Collu, M. Offshore floating vertical axis wind turbines, dynamics modelling state of the art. Part III: Hydrodynamics and coupled modeling approaches. Renewable Sustainable Energy Rev. 46, 2014b; I: 296-310.

[16] Cheng, Z, Madsen, HA, Chai, W, Gao, Z, Moan, T. A comparison of extreme structural responses and fatigue damage of semi-submersible type floating horizontal and vertical axis wind turbines. Renew. Energy 108, 2017a; 201-219.

[17] Cheng, Z, Madsen, HA, Gao, Z, Moan, T. A fully coupled method for numerical modeling and dynamic analysis of floating vertical axis wind turbines. Renew. Energy 107, 2017b; I: 604-619.

[18] Cheng, Z, Madsen, HA, Gao, Z, Moan, T. Effect of the number of blades on the dynamics of floating straightbladed vertical axis wind turbines. Renew. Energy 101, 2017c; I: 1285-1298.

[19] Lei, H, Zhou, D, Lu, J, Chen, C, Han, Z, Bao, Y. The impact of pitch motion of a platform on the aerodynamic performance of a floating vertical axis wind turbine. Energy 119, 2017; I: 369-383.

[20] Habtamu, B, Yingxue, Y. Double Multiple Stream Tube Model and Numerical Analysis of Vertical Axis Wind Turbine. Journal of Energy and Power Engineering 2011; I: 262-270.

[21] Dominique, R, Christian, C, Alexia, A, Alla, W. A floating foundation for offshore wind turbines. Journal of Renewable and Sustainable Energy, 2010, 2, 033104. https://doi.org/10.1063/1.3435339 